\title{
FINANCIAMENTOS VINCULADOS À RENDA FUTURA, SEGURIDADE SOCIAL E QUALIFICAÇÃO PROFISSIONAL: LITERATURA E PROPOSIÇÕES'
}

Paulo Meyer Nascimento²

\section{INTRODUÇÃO}

Este texto discute possibilidades de aplicação dos financiamentos vinculados à renda futura para remodelar programas de qualificação profissional e de seguro-desemprego, com potenciais desdobramentos para outras áreas da seguridade social e de financiamento público. Esse gênero de financiamento é amplamente discutido em Chapman, Higgins e Stiglitz (2014), em Libich e Macháček (2017) e em Nascimento (2019a), além de ser objeto de crescente literatura empírica. ${ }^{3}$ Duas são as suas espécies: os empréstimos com amortizaçóes condicionadas à renda (ECRs) e os income share agreements (ISAs). O primeiro é uma modalidade de crédito que tem balanceado eficiência e equidade em três décadas de operação para financiar estudos superiores na Austrália, na Nova Zelândia e na Inglaterra, norteando, desde então, reformas no financiamento estudantil em cada vez mais países. O segundo é um instrumento financeiro de capital próprio (equity) que aproxima o investimento na formação técnica e superior do modelo defendido por Milton Friedman em seu The role of government in education (publicado originalmente em Friedman, 1955). ${ }^{4}$

Finda esta introdução, a seçáo 2 contrasta os ECRs e os ISAs com os financiamentos convencionais e discute o potencial de ambos para financiar cursos técnicos e cursos de formação inicial e continuada (FIC). A seção 3 apresenta as linhas gerais de um modelo de seguridade social proposto por Stiglitz e Yun $(2005 ; 2013$; 2014) e uma proposta preliminar de remodelagem do seguro-desemprego no Brasil (Soares, 2019), que se mostra análoga a uma aplicação prática do modelo de Stiglitz e Yun, porém envolvendo fusão do seguro-desemprego com o Fundo de Garantia do Tempo de Serviço (FGTS). A seção 4 traz as consideraçóes finais.

\section{FINANCIAMENTOS VINCULADOS À RENDA FUTURA PARA A FORMAÇÃO PROFISSIONAL}

Mormente associados a investimentos em educação, os ECRs e os ISAs, as duas espécies do gênero financiamentos com pagamentos vinculados à renda futura, pressupóem que os

1. DOI: http://dx.doi.org/10.38116/bmt70/pfa1

2. Técnico de planejamento e pesquisa da Diretoria de Estudos e Políticas Sociais (Disoc) do Ipea.E-mail:<paulo.nascimento@ipea.gov.br>.

3. Ver, a título de exemplo, a edição especial da Economics of education review, prefaciada por Chapman e Doan (2019) e com simulações envolvendo brasileiros com nível superior reportadas por Dearden e Nascimento (2019).

4. Não confundir com o modelo de vouchers, que Friedman (1955) defende para financiamento da educação básica. 
reembolsos do crédito (no caso de um ECR) ou os pagamentos dos dividendos ao investidor (no caso de um ISA) são proporcionais à renda futura de quem é financiado e são recolhidos na fonte, por meio dos mesmos mecanismos de retenção de tributos. Sendo empréstimos, os ECRs atrelam-se a um saldo devedor; sendo investimentos de risco, os ISAs deixam de exigir pagamentos após decorrido o prazo estipulado em contrato, não importando se movimentaram valores muito além ou muito aquém do investimento inicialmente feito na formação do indivíduo (Nascimento, 2019b). Os ECRs podem ser entendidos, portanto, como ISAs com limite máximo de pagamento, como ilustra o gráfico 1, que também mostra como os perfis de pagamento de um e de outro instrumento se diferenciam do perfil de pagamento de um crédito convencional.

\section{GRÁFICO 1}

\section{Perfil de pagamento: crédito convencional x ECR x ISA}

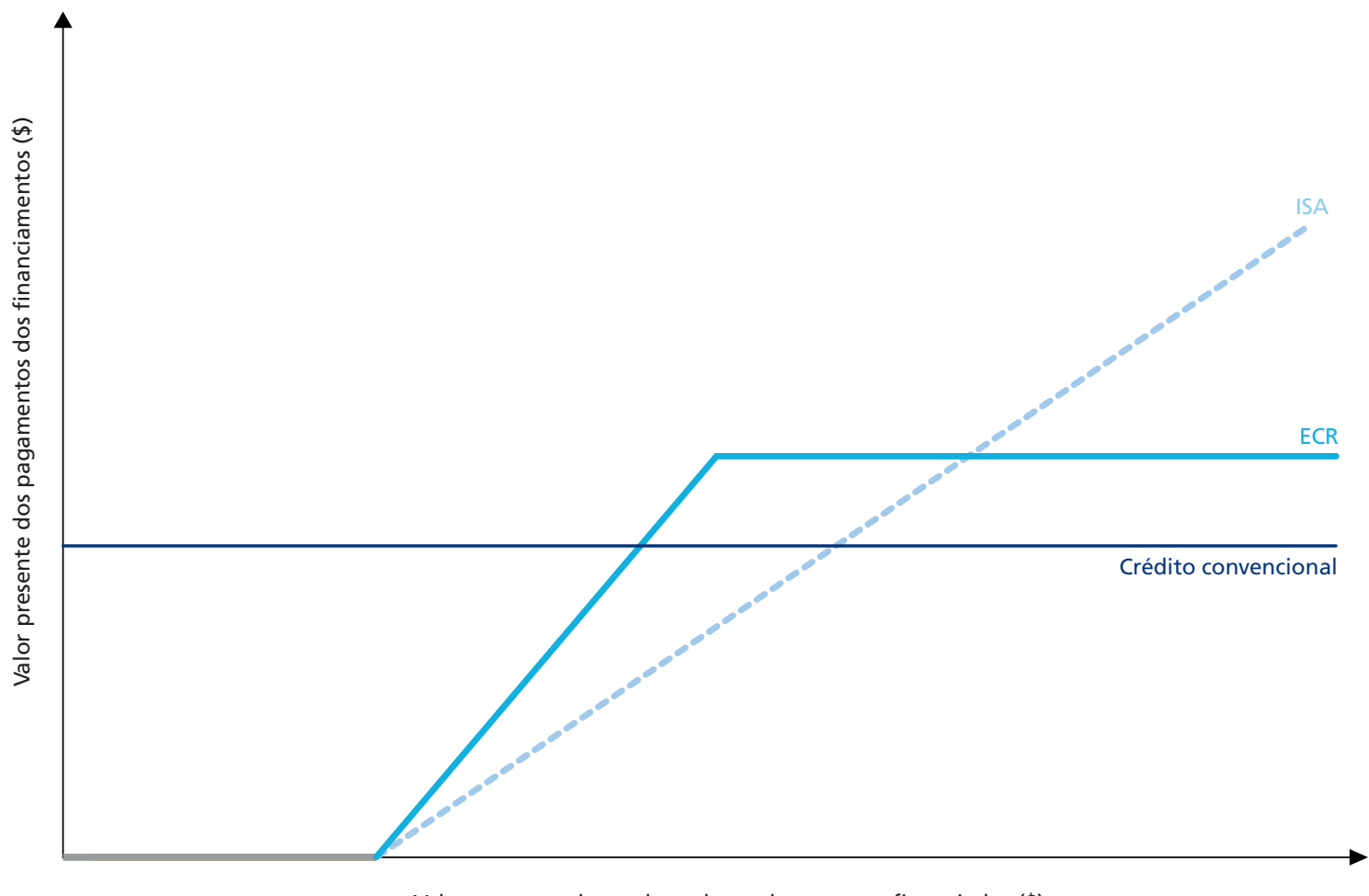

Valor presente da renda ou lucro dos agentes financiados (\$)

Fonte: Palacios (2019, com adaptações).

Um bom desenho de ECR pode prever taxas de juros de mercado, pois o devedor já é protegido contra eventuais choques negativos de renda que o impossibilitem de honrar seus pagamentos (que automaticamente são suspensos e a dívida, refinanciada, em caso de baixa renda). ECRs são fiscalmente mais sustentáveis do que créditos convencionais porque o único subsídio implícito refere-se ao não pagamento por insuficiência de renda (desaparece a figura da inadimplência), náo sendo necessários subsídios à taxa de juros em programas públicos de financiamento baseados nessa modalidade. 
Alguns dos devedores que se tornariam inadimplentes em um programa convencional de financiamento deixariam de sê-lo em um ECR, por duas razôes: $i$ ) os recolhimentos na fonte eliminam o não pagamento por ato discricionário do devedor; e ii) o refinanciamento automático da dívida (cujo prazo de amortização pode se estender por toda a vida do pagador) acaba por ampliar a possibilidade de reembolso integral, restando em aberto apenas parcelas de quem passou longos períodos com renda aferida insuficiente para honrar os pagamentos do empréstimo. Para o tomador do empréstimo, o ECR tem um caráter de seguro: pagamentos só serão exigidos se houver renda aferível compatível para arcar com eles, e mutuários cuja renda aferível seja sistematicamente baixa acabarão tendo parte ou o todo de sua dívida perdoada, após $n$ anos ou em caso de morte.

Já em um ISA, os pagamentos não são relacionados ao valor investido, e, sim, a um prazo e a um percentual da renda preestabelecidos em contrato. Pode, então, o investidor lucrar (se os dividendos pagos pelo beneficiário do investimento forem maiores do que o investimento em si) ou ter prejuízo (se os dividendos pagos forem menores do que o capital investido). Se o investidor for o Estado, eventuais perdas líquidas correspondem ao custo do subsídio concedido a quem não teve renda aferível suficiente para que o órgão de administração tributária recolhesse os pagamentos devidos. Eventuais ganhos líquidos significam, por sua vez, que a soma dos pagamentos feitos por quem veio a ter elevado padrão de renda supera as perdas de quem seguiu com baixo padrão de renda após ser beneficiário do ISA - podem ser entendidos, pois, como um superavit capaz de, a depender da decisão política, viabilizar a ampliação da política ou contribuir para melhorar o resultado fiscal.

Após mais de duas décadas financiando estudantes de graduação e de pós-graduação por meio de programas públicos de ECR, o governo australiano passou a oferecer esse tipo de empréstimo também para estudantes de cursos técnicos. Programa similar poderia ser pensado para o Brasil, o que, na prática, seria efetivar a ampliação do Fundo de Financiamento Estudantil (Fies) para a educação profissional e tecnológica, possibilidade prevista em lei, porém jamais colocada em prática. Não se deve perder de vista, contudo, o potencial dos ISAs para a efetivação de duas outras modalidades previstas na legislação do Fies, porém não implementadas de fato: o Fies-empresa e o Fies-técnico (Nascimento, 2018).

Por meio de ISAs, empregadores poderiam financiar a participação de colaboradores em cursos credenciados de FIC, de qualificaçáo profissional ou mesmo em cursos técnicos, de graduação ou de pós-graduação, com a garantia de que a Receita Federal do Brasil (RFB) viria a recolher, por tempo determinado, percentual da renda dessas pessoas como forma de remuneração do empregador pelo investimento feito. Regulamentar ISAs dessa forma

explicitaria o caráter de investimento da formação profissional e teria o potencial de remover um dos principais motivos mormente apontado como inibidor desse tipo de decisão por parte das empresas: o receio de investir em seus colaboradores para depois vê-los capturados por concorrentes, beneficiando ao final mais estes do que a si mesmas com os eventuais ganhos de produtividade propiciados pela qualificação custeada (Nascimento, 2018, p. 45). 
A regulamentação do ISA para educação profissional e tecnológica poderia prever também a participação de outros entes privados, como fundações, fundos de investimento, organizações não governamentais ou quaisquer entidades do terceiro setor, vinculadas ou não ao setor produtivo. A condiçáo seria que utilizassem recursos próprios para esse fim. O ISA teria o potencial de se tornar alternativa de investimento até mesmo para pessoas físicas, que estariam para o estudante assim como os investidores-anjos estão para as startups.

Compartilha-se, dessa maneira, o custo da formaçáo profissional no âmbito do próprio setor privado. Deve-se evitar, não obstante, que o governo venha a arcar com as perdas decorrentes de baixos rendimentos dos trabalhadores cuja formação profissional foi objeto de investimento. Sendo um investimento de risco, ganhos e perdas de um ISA devem recair sobre o investidor, não sobre o Estado.

Nascimento (no prelo) propóe um sistema nacional de financiamento estudantil que envolveria a oferta pública e privada de ECRs e de ISAs para financiar cursos FIC, cursos técnicos e cursos de nível superior. ${ }^{5}$ Em complemento a tal sistema, uma reformulação do seguro-desemprego que introduzisse um componente de autosseguro - financiado pelo FGTS poderia prever mecanismos que viabilizassem ao próprio desempregado financiar, com um ECR, estudos com vistas à sua recolocação no mundo do trabalho. A reformulação do segurodesemprego nesses moldes é o tema de discussão da próxima seção.

\section{MODELO STIGLITZ-YUN DE SEGURIDADE SOCIAL E A PROPOSTA DE FUSÃO DO FGTS COM O SEGURO-DESEMPREGO}

Diversos países - com destaque para Austrália, Inglaterra e Nova Zelândia - já aplicam ECRs em programas governamentais de financiamento a estudantes (Nascimento, 2019b). Palacios (2019) argumenta que governos otimizariam seus programas governamentais de assistência estudantil se oferecessem um mix de ECRs e ISAs. Até o momento, no entanto, estes vêm se popularizando em alguns países, aos poucos e exclusivamente, como produto privado de crédito educacional. ${ }^{6}$ Nascimento (no prelo) delineia uma proposta para o Brasil que prevê agentes públicos e privados financiando estudantes com ECRs e ISAs, sob a regulação de uma agência estatal ou paraestatal e com a RFB recolhendo os pagamentos. Para além do financiamento à educação não obrigatória, Chapman, Higgins e Stiglitz (2014) e Libich e Macháček (2017) abordam uma gama de outras possíveis aplicações dos financiamentos com pagamentos vinculados à renda futura.

Uma das potenciais novas aplicaçóes está relacionada à seguridade social. Aplica-se, neste caso, a ideia de "tomar emprestado" da renda pessoal futura para suavizar consumo e/ou se recolocar no mundo do trabalho ante choques como desemprego, acidentes e problemas de

5. 0 elo para viabilizar tal sistema seria a introdução de uma nova contribuição especial no Sistema Tributário Nacional (STN). 0 novo tributo justificaria a atuação da RFB no recolhimento dos pagamentos vinculados à renda futura - como se depreende da exposição de Melo (2019) - e poderia ser regulamentado de maneira tal que viabilizasse um sistema público-privado de financiamento estudantil, figurando apenas formalmente (isto é, da porta da RFB para dentro) como um tributo. Ver detalhes em Nascimento (no prelo).

6. Ver Bair e Cooper (2019). No Brasil, não são regulamentados, embora possam ser encontradas notícias de startups e fintechs ofertando esse tipo de financiamento a partir de 2019 - ver Baraldi (2020), Startup... (2020) e Le Roux (2020). 
saúde. Pode-se pensar, ainda, em incorporar o financiamento de outras necessidades individuais ou domiciliares, como extensão da licença parental ou aquisição da casa própria. Modelo nessa linha tem sido proposto por Stiglitz e Yun $(2005$; 2013; 2014).

Na proposição original (Stiglitz e Yun, 2005), os autores apresentam um modelo que integra o seguro-desemprego com um programa de pensáo. Permite, entáo, que os trabalhadores saquem valores de seus fundos de aposentadoria para financiar seu consumo durante episódios de desemprego. Se os momentos de desemprego fossem relativamente curtos em relaçáo aos períodos em que a pessoa permanecesse empregada ou aposentada, o sistema ótimo envolveria um seguro-desemprego exclusivamente financiado por autosseguro - isto é, pelos empréstimos garantidos pelo fundo de pensáo/aposentadoria em nome da pessoa. Argumentam os autores que um sistema nesses moldes tenderia a aumentar o bem-estar, à medida que viabilizaria suavização intertemporal do consumo sem atenuar os incentivos à busca por um novo emprego.

Os próprios autores ressaltam (Stiglitz e Yun, 2014) que o maior risco associado a tal modelo seria esgotar o fundo individual de pensão/aposentadoria, deixando os tomadores de empréstimo desassistidos na velhice. Esse seria particularmente o caso entre indivíduos que enfrentassem prolongadas ou recorrentes situaçóes de desemprego ao longo de sua vida ativa. No limite, o saldo do fundo de pensão/aposentadoria de algumas pessoas poderia vir até a se mostrar negativo quando elas passassem a depender desses recursos justamente para financiar o que fundos dessa natureza deveriam financiar: a aposentadoria.

É aí que, na visão dos autores, os ECRs contornariam de maneira apropriada o problema: nos casos de segurados para quem resultados adversos no mercado de trabalho (isto é, desemprego recorrente ou prolongado) terminassem por dilapidar o saldo de seu fundo individual de pensão/aposentadoria, parte ou a totalidade do saldo devedor seria perdoada, a fim de restaurar uma aposentadoria minimamente compatível com o padrão de renda e com as contribuiçóes observadas ao longo da sua vida ativa (Stiglitz e Yun, 2014). Os ECRs atuam aqui de forma análoga à sua aplicação para financiar formação técnica e superior: o reembolso do empréstimo não é apenas proporcional à renda aferida ao longo da vida; há também um teto de pagamento equivalente ao montante principal mais juros, para quem obtém bom desempenho no mercado de trabalho, enquanto que quem acaba enfrentando maiores dificuldades na ativa tem a proteçáo do perdáo de parte ou da totalidade da dívida ao final da vida, se seu padrão de renda não permitir pagá-la sem que se caia em situação de pobreza.

A incorporação dos ECRs no modelo vem em Stiglitz e Yun (2013), quase dez anos depois da modelagem inicial apresentada em Stiglitz e Yun (2005).7 Passam a modelar, então, a combinação ótima entre seguro-desemprego, pago pelo governo, e ECRs, a serem pagos pelo saldo futuro do fundo individual de pensão/aposentadoria. O modelo mostra que, se a incidência de desemprego de longa duração for relativamente baixa, a combinaçáo ótima acarreta mais empréstimos e menor benefício de seguro-desemprego para os jovens do que

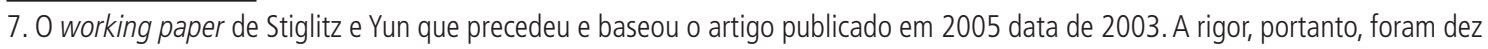
anos até a incorporação dos ECRs ao modelo. 
para os idosos, do que se depreende que o sistema de seguridade proposto viabilizaria maior consumo para os jovens desempregados do que para quem se encontrar em desemprego em idades mais avançadas.

Stiglitz e Yun chamam o modelo proposto de sistema integrado de seguro vitalício e argumentam que também poderia incorporar outros riscos, desde que estes náo se mostrassem perfeitamente correlacionados um com o outro. Mesmo que os riscos estejam parcialmente correlacionados, a integração levaria a alguma melhoria do bem-estar. Para eles, em vez de executar programas de seguro separadamente, os governos poderiam (e muitas vezes deveriam) elaborar um programa de seguro vitalício integrado, cobrindo também riscos relativos, por exemplo, a invalidez e saúde, sendo os ganhos de bem-estar maiores quanto menor a correlação entre esses riscos.

$\mathrm{Na}$ prática, o sistema proposto pressupóe um benefício-base financiado por tributos, dispondo o beneficiário da possibilidade de estendê-lo contraindo empréstimos. Estes poderiam ser usados para ampliar o número de parcelas ou o montante pago como seguro-desemprego, para financiar cursos de requalificaçáo profissional, para estender licença parental, para custear tratamentos de saúde, para financiar casa própria ou para uma série de outros usos possíveis e consistentes com os objetivos de um sistema de bem-estar social.

Os empréstimos seriam ECRs consignados ao saldo que, no momento em que se contrai a dívida, é possível projetar para seu fundo de pensão/aposentadoria no futuro, quando os saques ocorrerão para cobrir a aposentadoria da pessoa e - desde que o capital total esperado para o fundo se concretize - os reembolsos dos ECRs tomados ao longo da vida. Idealmente, os parâmetros do sistema devem ser calibrados de maneira tal que, no agregado, o governo gaste menos com seguro-desemprego e não tenha de fazer desembolsos líquidos para cobrir a parcela de não pagamento dos ECRs - afinal, a taxa de juros desses empréstimos pode incorporar a expectativa de perda decorrente de náo pagamento do $\mathrm{ECR},{ }^{8}$ dividindo a conta entre os próprios segurados.

O sistema proposto por Stiglitz e Yun poderia ser exequível na realidade brasileira se envolvesse o FGTS. A complementação do seguro-desemprego, da licença parental, do auxíliodoença ou de algum outro benefício da seguridade social poderia advir de saques do FGTS mesmo quando a pessoa ainda não dispusesse de saldo suficiente, desde que limitados os saques a situaçóes específicas e a montantes compatíveis com o saldo futuro esperado, dado o perfil de carreira da pessoa e o tempo que lhe resta de vida laboral.

É nessa linha que se desenrola uma proposta preliminar apresentada por Sergei Soares, pesquisador do Ipea, em conferência realizada no instituto em julho de 2019. Ele propóe a fusão do FGTS e do seguro-desemprego, de forma a viabilizar mais tempo de seguro-desemprego para quem realmente não consegue encontrar trabalho, ao mesmo tempo que se incentiva o retorno ao trabalho e se otimiza o uso de recursos públicos para o seguro-desemprego (Soares,

8. Não pagamento que se dá exclusivamente por insuficiência de renda, dado que a coleta dos pagamentos é na fonte e que o modelo assume irrelevantes os efeitos de eventuais artifícios de elisão e de evasão sobre as contribuições compulsórias para o fundo individual de pensão/aposentadoria. 
2019). No cômputo final, haveria, de um lado, economia de recursos públicos e, de outro, maior benefício a quem permanecesse longos períodos desempregado. A parcela do segurodesemprego a ser financiada por tributos seria reduzida, mas o benefício seria alargado em tempo e montante com o uso do FGTS.

Na proposta preliminar de Soares (2019), o Fundo de Amparo ao Trabalhador (FAT) pagaria a todo e qualquer trabalhador desempregado um benefício mensal equivalente a $80 \%$ do salário mínimo vigente, benefício esse que poderia ser acrescido por saques do FGTS até determinado limite. As mudanças permitiriam estender o benefício do seguro-desemprego por até dezoito meses (a legislação em vigor prevê no máximo cinco parcelas), sem acarretar aumento de despesas para o governo e viabilizando o recebimento de benefícios maiores e por mais tempo para quem efetivamente necessitasse.

Em linha com a modelagem proposta por Stiglitz e Yun (2013) e extrapolando a proposta preliminar de Soares (2019), ECRs atrelados ao saldo futuro do FGTS poderiam, igualmente, ser colocados à disposição do trabalhador para financiar cursos de requalificação profissional, extensão de licença parental, tratamentos de saúde, aquisição de casa própria, entre outros riscos que não fossem perfeitamente correlacionados ao risco de desemprego. O desafio seria ajustar da melhor forma os parâmetros que definiriam o montante disponível para ECRs a cada momento, de maneira a minimizar os riscos de não haver saldo suficiente para reembolsá-los no futuro.

\section{CONSIDERAÇÕES FINAIS}

Financiamentos com pagamentos vinculados à renda futura têm se consolidado em variadas partes do mundo como modalidades de financiamento estudantil superiores aos mecanismos tradicionais de crédito educacional. Os ECRs mostram-se, há três décadas, eficazes instrumentos de política na promoção da eficiência e da justiça social no campo da assistência estudantil. Os ISAs vêm aos poucos ganhando importância como produto privado de investimento em formação profissional, podendo vir a também se tornar relevantes ferramentas de política pública. Ambos são espécies de financiamento com pagamentos vinculados à renda futura. Este texto buscou discutir particularmente o potencial dos ISAs para financiar formação profissional no Brasil e apresentou as linhas gerais de um modelo que poderia transformar o seguro-desemprego e outros benefícios de seguridade social em um sistema integrado de seguro vitalício, em que benefícios-base custeados por tributos poderiam ser suplementados por ECRs, tendo por colateral o saldo futuro do FGTS do trabalhador.

No modelo proposto por Stiglitz e Yun $(2005$; 2013; 2014), os níveis de seguro e de suavizaçáo do consumo intertemporal aumentam - sem atenuar os incentivos à busca - quando o seguro-desemprego financiado pelo contribuinte pode ser complementado pelo autosseguro. Esse autosseguro adviria de empréstimos garantidos pela renda futura do próprio indivíduo desempregado. Não se trata de um consignado: a ideia é que, enquanto em idade ativa, a pessoa possa tomar emprestado do saldo futuro de seu fundo de garantia. Apresentou-se, então, proposta preliminar de Soares (2019) para fusão do seguro-desemprego com o FGTS. Argumenta-se, neste trabalho, que a proposta preliminarmente apresentada por Soares (2019) 
pode ser aprofundada para aproximá-la do sistema integrado de seguro vitalício modelado por Stiglitz e Yun (2013), incorporando a previsão de ECRs para financiar requalificação profissional, extensão de licença parental, tratamentos de saúde e aquisição de casa própria, entre outros riscos náo perfeitamente correlacionados ao risco de desemprego.

$\mathrm{O}$ uso de ECRs e ISAs para financiar estudantes é recorrentemente discutido na literatura. Nascimento (no prelo) apresenta proposta que, levando em conta a realidade e as instituiçóes brasileiras, implementaria no Brasil um sistema nacional de financiamento estudantil baseado nessas duas espécies de financiamento com pagamentos vinculados à renda futura. A literatura internacional - por exemplo, a coletânea de Chapman, Higgins e Siglitz (2014) e o artigo de Libich e Macháček (2017) - discute um variado leque de possíveis aplicaçóes para além da educação, de auxílios emergenciais a estímulo à inovação. No Brasil, aplicaçóes fora do contexto da formação profissional começam a surgir também - a exemplo da proposta de Nogueira et al. (2020), que envolve um pacote de socorro a micro e pequenas empresas envolvendo ECRs. $\mathrm{O}$ presente trabalho inaugura uma agenda de pesquisa que passará por estudos de possíveis aplicaçóes para o Brasil do sistema integrado de seguro vitalício proposto por Stiglitz e Yun $(2013$; 2014), tendo como ponto de partida a proposta preliminar de Soares (2019) para a fusão do FGTS com o seguro-desemprego.

\section{REFERÊNCIAS}

BAIR, S.; COOPER, P. The future of income-share agreements. Manhattan: Manhattan Institute, Mar. 2019. Disponível em: <https://bit.ly/3n9p9Z4>. Acesso em: 17 abr. 2019.

BARALDI, A. O que é Income Share Agreement (ISA)? Medium, 22 Jan. 2020. Disponível em: <https://bit.ly/3dcrPPZ>. Acesso em: 28 maio. 2020.

CHAPMAN, B.; DOAN, D. Introduction to the Special Issue "Higher Education Financing: Student Loans”. Economics of Education Review, v. 71, p. 1-6, Aug. 2019.

CHAPMAN, B.; HIGGINS, T.; STIGLITZ, J. (Orgs.). Income contingent loans: theory, practice and prospects. Houndmills; New York: Palgrave Macmillan, 2014.

DEARDEN, L.; NASCIMENTO, P. M. Modelling alternative student loan schemes for Brazil. Economics of Education Review, v. 71, p. 83-94, Aug. 2019. Disponível em: <https://bit. ly/32gEiNh>. Acesso em: 5 set. 2019.

FRIEDMAN, M. The role of government in education. In: SOLO, R. A. (Ed.). Economics and the public interest. New Brunswick: Rutgers University Press, 1955.

LE ROUX, M. Le Wagon Brasil lança a opção ISA (Income Share Agreement). Le Wagon, 23 abr. 2020. Disponível em: <https://bit.ly/36AstEC>. Acesso em: 28 maio 2020.

LIBICH, J.; MACHÁČEK, M. Insurance by government or against government? Overview of public risk management policies. Journal of Economic Surveys, v. 31, n. 2, p. 436-462, 2017.

MELO, A. L. Possíveis contribuiçóes das escrituraçóes tributárias digitais para automatização da cobrança do Fies. In: CONFERÊNCIA INTERNACIONAL SOBRE FINANCIAMENTO VINCULADO À RENDA: ALTERNATIVAS PARA O ENSINO SUPERIOR E OUTRAS 
ÁREAS DE POLÍTICA PÚBLICA, 2019, Brasília, Distrito Federal. Anais... Brasília: Ipea; ANU, 2019. Disponível em: <https://bit.ly/2lGl8A4>. Acesso em: 31 jul. 2019.

NASCIMENTO, P. M. Pronatec 2.0: Uma proposta de reformulação fundamentada em financiamentos contingentes à renda. Radar: tecnologia, produçáo e comércio exterior, n. 58, p. 43-46, dez. 2018. Disponível em: <https://bit.ly/36xSdDJ>. Acesso em: 28 set. 2020.

- (Org.). Financiamentos com pagamentos vinculados à renda futura: a produção do Ipea até 2018. Brasília: Ipea, 2019a. Disponível em: <https://bit.ly/2GbM0is>. Acesso em: 3 jul. 2019.

. Prefácio. In: NASCIMENTO, P. M. (Org.). Financiamentos com pagamentos vinculados à renda futura: a produção do Ipea até 2018. Brasília: Ipea, 2019b. Disponível em: <https://bit.ly/2GbM0is>. Acesso em: 3 jul. 2019.

Proposta de um sistema nacional de financiamento estudantil com pagamentos vinculados à renda futura: financiamento e fontes de recursos. Brasília: Ipea, no prelo.

NOGUEIRA, M. O. et al. SOS Covid-19 - vacinação em massa para as micro e pequenas empresas: uma proposta de crédito contingente ao faturamento para os pequenos negócios fazerem frente aos impactos da Covid-19 no Brasil. Niterói: Itapuca/Cocuyo, 2020. Disponível em: <https://bit.ly/3kZ10Cr>. Acesso em: 28 set. 2020.

PALACIOS, $M$. The relationship between income share agreements and income contingent loans, and why we need both. In: CONFERENCIA INTERNACIONAL SOBRE FINANCIAMENTO VINCULADO À RENDA: ALTERNATIVAS PARA O ENSINO SUPERIOR E OUTRAS ÁREAS DE POLÍTICA PÚBLICA, 2019, Brasília, Distrito Federal. Anais... Brasília: Ipea; ANU, 2019. Disponível em: <https://bit.ly/2VtF48x>. Acesso em: 31 jul. 2019.

SOARES, S. S. D. Uma proposta de fusão do Fundo de Garantia por Tempo de Serviço e seguro desemprego. In: CONFERÊNCIA INTERNACIONAL SOBRE FINANCIAMENTO VINCULADO A RENDA: ALTERNATIVAS PARA O ENSINO SUPERIOR E OUTRAS ÁREAS DE POLÍTICA PÚBLICA, 2019, Brasília, Distrito Federal. Anais... Brasília: Ipea; ANU, 2019. Disponível em: <https://bit.ly/3jj4vDo>. Acesso em: 31 jul. 2019.

STARTUP que forma desenvolvedor e cobra após aluno conseguir emprego capta $\mathrm{R} \$ 42$ milhôes. Isto é Dinheiro, 28 fev. 2020. Disponível em: <https://bit.ly/3epvfzd>. Acesso em: 28 maio 2020.

STIGLITZ, J. E.; YUN, J. Integration of unemployment insurance with retirement insurance. Journal of public economics, v. 89, n. 11, p. 2037-2067, 2005. Disponível em: <https://bit. ly/3maNBHW>. Acesso em: 31 ago. 2017.

Optimal provision of loans and insurance against unemployment from a lifetime perspective. Cambridge, MA: National Bureau of Economic Research, 2013. Disponível em: <https://bit.ly/37tWzMz>. Acesso em: 20 set. 2015.

. Income contingent loans for the unemployed: a prelude to a general theory of the efficient provision of social insurance. In: CHAPMAN, B.; HIGGINS, T.; STIGLITZ, J. E. (Orgs.). Income contingent loans: theory, practice and prospects. Houndmills; New York: Palgrave Macmillan, 2014. 
